\title{
Projeto: Treinamento para a OBMEP
}

\author{
Marcelo Renan Augusto Ferreira \\ Universidade Tecnológica Federal do Paraná \\ marceloraferreira@gmail.com \\ Lucas Gabriel Ribeiro de Souza \\ Universidade Tecnológica Federal do Paraná \\ Lucas.gabrieel1994@gmail.com \\ Sérgio Matsue Filho \\ Universidade Tecnológica Federal do Paraná \\ smatsuef@gmail.com \\ Milton Kist \\ Universidade Tecnológica Federal do Paraná \\ miltonkist@utfpr.edu.br
}

\begin{abstract}
Resumo:
A experiência a ser relatada faz parte do Programa Institucional de Bolsa de Iniciação a Docência (PIBID) da Universidade Tecnológica Federal do Paraná - Campus Cornélio Procópio, que tem por objetivo a inserção dos estudantes no contexto das escolas públicas desde o início da sua formação acadêmica para que desenvolvam atividades didático-pedagógicas sob orientação de um docente da licenciatura e de um professor da escola.

Como parte das atividades desenvolvidas no PIBID durante certo período foram feitas observações em salas de aula de diferentes níveis da educação básica, foram estudadas também algumas metodologias tais como: Resolução de Problemas, Investigação Matemática, Modelagem Matemática, Tecnologias da Informação e Comunicação e Jogos Matemáticos, para que a partir de então começássemos a desenvolver algo que viesse contribuir tanto para a formação dos alunos inseridos na educação básica tanto para nós enquanto graduandos.

Tendo em vista que a maior parte dos projetos são destinados aos alunos com maior dificuldade na disciplina de Matemática e possuem um menor rendimento, então resolveu-se desenvolver um projeto no qual é visado o trabalho com os alunos que demonstram um maior rendimento na disciplina de Matemática, o qual eles receberiam um treinamento para a Olimpíada Brasileira de Matemática das Escolas Públicas (OBMEP) edição 2013/2014.

A primeira justificativa desse projeto é exatamente o "esquecimento" desses alunos em sala de aula, os que se destacam entre poucos e terminam rapidamente as atividades em sala ficam ociosos, pois mesmo com a Lei de Diretrizes e Bases da Educação Nacional (LDB), no 9.394/96 (Brasil, 1996), no Capítulo III, art. $4^{\circ}$, inciso III, diz que é dever do Estado garantir o "atendimento educacional especializado gratuito aos educandos com necessidades especiais, preferencialmente na rede regular de ensino"isso não ocorre uma vez que os professores tendem a ajudar os que ainda não entenderam o conteúdo, "esquecendo" assim, quem aprendeu, ressaltando que a LDB trata de necessidades especiais tanto as dificuldades quanto as facilidades de alunos.
\end{abstract}

A segunda justificativa é o que a OBMEP pode proporcionar a vida acadêmica de um aluno: 
- A produção e distribuição de material didático de qualidade, como apostilas e banco de questões, também disponível nesta página;

O Programa de Iniciação Científica Jr. (PIC), para os medalhistas estudarem Matemática por 1 ano, com bolsa do Conselho Nacional de Desenvolvimento Científico e Tecnológico (CNPq);

- $\quad$ O Programa de Iniciação Científica - Mestrado (PICME), para medalhistas que estejam cursando graduação com bolsas do CNPq (IC) e CAPES (Mestrado);

- $\quad$ A Preparação Especial para Competições Internacionais (PECI), que prepara medalhistas de ouro selecionados pela excepcionalidade de seus talentos para competições internacionais;

- $\quad$ O POTI - Polos Olimpícos de Treinamento Intensivo, que pretende democratizar e ampliar o acesso dos alunos brasileiros a treinamento para competições matemáticas;

a criação dos Clubes de Matemática, que vão propiciar outros modos de estudo da matemática entre alunos e professores, com atividades interessantes e em ambiente interativo

Os encontros acontecem às sextas-feiras, no período vespertino a partir das $15 \mathrm{~h} 30 \mathrm{com}$ a duração 2 horas. Em primeiro momento a aplicação de exercícios propostos nos anos anteriores pela OBMEP é o método utilizado nos encontros, são impressas listas contendo 6 exercícios separados nas áreas de Geometria, Álgebra e Análise Combinatória. É limitado um tempo para a resolução de cada exercício proposto, a fim de que ao término de cada um haja um debate sobre a resolução de cada aluno (que conseguiu imaginar um meio solucionar o problema), é solicitado para que tais alunos resolvam no quadro explicando o seu respectivo desenvolvimento, portanto compartilhando sua maneira de pensar, que difere de outros coelgas, mostrando as várias formas de resolução de um mesmo exercício, é interessante ressaltar sobre essas resoluções foi é que algumas delas diferem das que estão contidas no caderno de questões da OBMEP.

Em segundo momento serão ensinados conteúdos de ensino médio com o intuito que a percepção e a facilidade com a disciplina de Matemática seja trabalhada e melhor desenvolvida, já que de certa forma algumas questões do Nível 2 da OBMEP se tratam de conteúdos relacionados ao ensino médio, então os exercícios voltados para as áreas já citadas devem entrar nos conhecimentos que os alunos já possuem, aplicando certas atividades se espera ver o quanto treinamento para a OBMEP estaria ou não dando resultados significativos para o processo de aprendizagem do aluno.

Palavras-chave: OBMEP, PIBID, Matemática, aprendizagem.

\section{Referências:}

BRASIL. Senado Federal. Lei de Diretrizes e Bases da Educação Nacional: no 9394/96. Brasília: 1996.

OBMEP. Apresentação. Disponível em: < http://www.obmep.org.br/apresentacao.html> Acesso em 03/10/2013. 